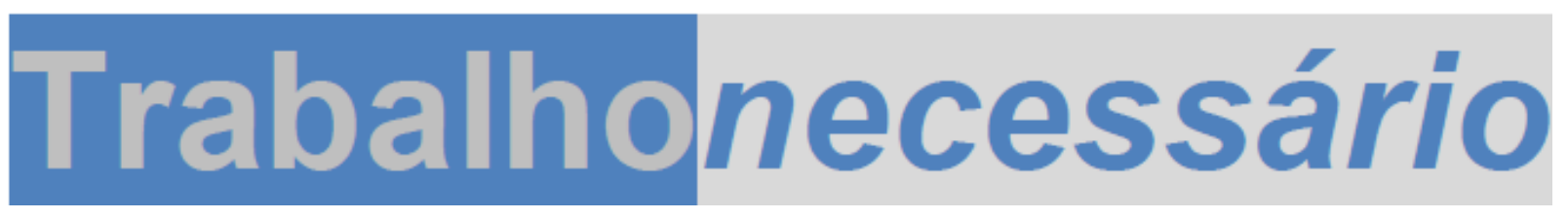

Issn: 1808 - 799X

ano 10, no $15-2012$

\title{
PEDAGOGIA DO TRABALHO E INTELIGÊNCIA OPERÁRIA: CONTRIBUIÇÕES NA PERSPECTIVA DA PRODUÇÃO ASSOCIADA ${ }^{1}$
}

\author{
Geraldo Márcio Alves dos Santos ${ }^{2}$
}

\begin{abstract}
Resumo: Este artigo propõe um debate sobre o principio educativo do trabalho na produção associada. Além da revisão da literatura, nosso foco é uma análise da experiência dos metalúrgicos da Metalcoop, uma cooperativa industrial localizada em Salto-SP. Trazemos como interrogação que a potência criativa dos trabalhadores na produção associada reforça e traz novos elementos sobre o estatuto epistemológico da experiência. Como aporte teórico, recorremos à tradição marxista sobre o processo de trabalho e seu inerente caráter educativo, também, com autores que debatem a produção associada (Singer, 2002; 2003; Tiriba, 2001) e com aqueles que interrogam o estatuto social da técnica, da ciência e da tecnologia. (Braverman, 1987; Marx, 1982; 1987; Novaes, 2007; Pinto; 2004).
\end{abstract}

Palavras-Chave: Saberes tácitos; maquinaria, processo de trabalho e cooperativismo

Abstract: This article proposes a debate on the educational principle of labor in production associated. Besides the literature review, we focus on an analysis of the experience of the metallurgical METALCOOP, an industrial cooperative located in Salto-SP. We bring to question the power of creative production workers associated reinforces and brings new elements on the epistemological status of the experience. As a theoretical contribution, we resorted to the

\footnotetext{
${ }^{1}$ Este artigo contém uma análise parcial da tese, Pacto para viver: a mobilização de saberes na produção associada, gestão e organização do processo de trabalho e maquinaria em uma indústria metalúrgica (Santos, 2010), defendida em Abril de 2010, sob orientação da Professora Dra. Sonia Maria Rummert a quem eu dedico este artigo.

${ }^{2}$ Torneiro Mecânico, Historiador, Mestre em Educação FAE/UFMG e Doutor em Educação pela Universidade Federal Fluminense. Professor adjunto da Universidade Federal de Viçosa.
} 


\section{Trabalhonecessário}

Issn: $1808-799 X$

ano 10, no $15-2012$

Marxist tradition on the work process and its inherent educational, too, with authors who discuss the associated production (Singer, 2002; 2003; Tiriba, 2001) and those who question the social status of the technique, science and technology. (Braverman, 1987; Marx, 1982, 1987; Novaes, 2007; Pinto, 2004).

Keywords: Knowledge tacit; work process and cooperativeness 


\section{Trabalhonecessário}

Issn: $1808-799 X$

ano 10, no $15-2012$

\section{Introdução}

Buscaremos neste texto trazer alguns elementos sobre a mobilização de saberes pelos trabalhadores em uma indústria metalúrgica em regime de produção associada, ilustrando que a eficiência técnica neste processo de trabalho é dada em uma reconfiguração da hierarquia de saberes, em que a experiência operária interroga a ciência e a tecnologia apropriada pela engenharia. Temos, também, evidências de que na interface com a maquinaria os trabalhadores, por meio de seus saberes, articulam ciência, tecnologia e técnica. Por fim, trazemos ilustrações de que relações de trabalho menos coercitivas potencializam o princípio educativo do trabalho.

O debate sobre o principio educativo do trabalho indica que, antes de ser um objeto de análise, os saberes dos trabalhadores já se apresentam na empiria, no processo de trabalho (Kuenzer, 1997; Frigotto, 2001; Nosella, 1992; Santos, 2004; 2010), evidencia, portanto, o trabalho como uma categoria fundante da humanidade. (Marx, 1985; Gramsci, 1985; Antunes, 2001). Vejamos uma aproximação do trabalho com a dimensão educativa:

Num primeiro sentido, o trabalho é princípio educativo na medida em que determina pelo grau de desenvolvimento social atingido historicamente, o modo de ser da educação em seu conjunto. Nesse sentido, aos modos de produção correspondem modos distintos de educar com uma correspondente forma dominante de educação. E um segundo sentido, o trabalho é princípio educativo na medida em que coloca exigências específicas que o processo educativo deve preencher, em vista da participação direta dos membros da sociedade no trabalho socialmente produtivo. Finalmente, o trabalho é princípio educativo num terceiro sentido, à medida que determina a educação como modalidade específica 


\section{Trabalhonecessário}

Issn: 1808 - 799X

ano 10, no $15-2012$

e diferenciada de trabalho: o trabalho pedagógico. (Savianni apud Frigotto, Ciavatta e Ramos, 2005, p. 31).

Nesse sentido, a idéia de um princípio educativo do trabalho esta imbricada com o desenvolvimento humano, portanto, sempre atual. Por outro lado, na medida em que as transformações no mundo trabalho fazem aumentar a presença da maquinaria em detrimento do trabalho humano, alguns pesquisadores supervalorizaram a presença da ciência no processo de trabalho, muito se falou no fim da sociedade do trabalho e no esgotamento do trabalho como categoria sociológica.

Esse texto traz reflexões sobre a importância do trabalho vivo no processo de trabalho e, como este, em grande medida, se apóia em saberes oriundos da experiência. Trazemos, também, pistas de como o trabalho enseja novas relações sociais quando a divisão do trabalho e a hierarquia de saberes são questionadas, no caso em análise, pela produção associada. Portanto, valoriza-se aqui a categoria trabalho porque valorizamos a experiência dos trabalhadores, ainda que essa careça da legitimidade que the cabe. Eis uma das perspectivas caras ao Campo Trabalho e Educação, a legitimidade dos saberes dos trabalhadores.

Isso exige, em nosso olhar, além de um referencial que perceba 0 imbricamento da técnica, da ciência e da tecnologia com o social e o político, uma postura que não anule o trabalhador como um sujeito capaz de produzir reflexões sobre o seu próprio trabalho. (Santos, 1997; 2000; Tiriba, 2001; 2004). Para os trabalhadores, também, fica a tarefa de se apropriar dos saberes e da experiência produzidas pela academia, recuperar a dimensão da totalidade fragmentada no chão de fábrica e nos saberes escolares. Assim, a 


\section{Trabalhonecessário}

Issn: 1808 - 799X

ano 10, no $15-2012$

recuperação do estatuto epistemológicos dos saberes dos trabalhadores é, também, obra dos próprios trabalhadores. Vejamos as contribuições dos metalúrgicos que se associaram para produzir na Metalcoop.

\section{A marcha dos trabalhadores pela reapropriação dos meios de produção}

Desde fins do século XVIII, os trabalhadores encaminharam diversas formas de resistência ao trabalho assalariado. (Marx, 1985; Singer, 1998). Para Novaes (2007):

(...) durante todo o século 19, as associações e as cooperativas figuraram, com certa notoriedade, dentre as principias formas de organização e de resistencia dos trabalhadores ao processo de expansão mundial do capitalismo. Deste período até a comuna de París, em 1871, a associação foi o principio articulador de relações sociais igualitárias, coletivistas e democráticas dos trabalhadores. Princípio este que se espalhou pelo que era então a Europa. (2007, p. 16).

No início do século XIX, reflexões e iniciativas empíricas apontam a possibilidade dos trabalhadores assumirem o controle da produção material. Dentre outras, a presença de Robert Owen (1773-1858) ${ }^{3}$ no movimento cooperativista, o qual, com o passar do tempo acaba incomodando a elite inglesa, enquanto sua ação se limitava apenas a de filantropo, só receberá riquezas, aplausos, honra e fama (...). (Engels, 1962, p. 20). A aproximação de Owen com os sindicatos muda a perspectiva de cooperativismo, que passa a se inscrever pela e na luta de classes; greves eram encaminhadas para

\footnotetext{
${ }^{3}$ Aqui, destacamos mais a figura de Owen, já que a literatura que abordamos confere a este um status de um homem de idéias, e, também de prática no movimento cooperativista. A ligação de Owen com o cooperativismo se inicia quando ele em sua própria propriedade constrói casas para os trabalhadores, escola para as crianças e abre loja para vender produtos com preços acessíveis e reduz a jornada de trabalho. Para Hobsbawm (1979), Marx e Engels faziam distinção entre Owen e os demais "utópicos"Saint Simon e Fourier-, Ao contrário de Fourier e Saint-Simon, Owen é definido como "comunista" por Marx e Engels desde o início dos anos 40: então, como mais tarde, Engels ficou impressionado com o bom senso prático e o caráter empresarial com que Owen projetaria as suas comunidades utópicas (...), Marx, todavia, não tinha dúvida de que Owen, do ponto de vista teórico, era inferior aos franceses. (Hobsbawm, 1979, p.45- 46).
} 


\section{Trabalhonecessário}

Issn: 1808 - 799X

ano 10, no $15-2012$

favorecer a demanda pelos produtos das cooperativas concorrentes no setor paralisado. (Singer, 1998).

O aumento das iniciativas dos trabalhadores rumo às cooperativas incitou uma forte reação dos capitalistas, amparados pelo Estado, período de condenações e ameaças aos líderes e aos trabalhadores de um modo geral. (Thompson, 1987). A partir de 1830, há um refluxo do cooperativismo que ressurge apenas uma década depois com a experiência de Rochdale em 1844, os quais adotaram regras para fortalecer o cooperativismo ${ }^{4}$, mas, acabaram por aceitar a participação de acionistas, assim nem todos os sócios eram trabalhadores ${ }^{5}$. Segundo Singer (1998), a expansão de Rochdale foi acompanhada por uma expansão do cooperativismo na Grã-Bretanha ao ponto de ser difícil de fazer uma diferenciação entre as cooperativas e as empresa de sociedade anônima. Concorrem para o refluxo qualitativo do cooperativismo, e não o seu desaparecimento, as conquistas políticas e econômicas dos

\footnotetext{
4 A primeira era que a sociedade seria governada democraticamente, cada sócio tendo um voto, independente do capital que tenha investido (...) A segunda era que a sociedade seria aberta a qualquer pessoa que quisesse se associar, desde que integre uma cota mínima e igual para todos de capital (...) A terceira (..) o capital investido faria jus a uma taxa fixa de juros(...). A quarta (...): o excedente que sobra depois de remunerado o capital deve ser distribuído entre os sócios conforme o valor de suas compras. Pretendia-se com isso estimular os cooperados a utilizar os serviços da sociedade (...). A quinta estabelece que a sociedade só venderia a vista. Esta foi uma regra dura para os trabalhadores expostos as crises industriais periódicas, em que muitos ficavam desempregados. Mas, por isso mesmo, cooperativas que vendiam fiado acabavam falindo (...). A sexta manda a sociedade vender apenas produtos puros e de boa qualidade. (...). A sétima ditava o desenvolvimento da educação dos sócios nos princípios do cooperativismo. (...). A oitava determinava que a sociedade seria neutra política e religiosamente (...). (Singer, 1998, p. 101-102).

5 Marx (1979) analisa a convivência das cooperativas em meio à produção capitalista com um mistura de otimismo e ceticismo: As fábricas capitalistas das cooperativas dos trabalhadores, no interior do regime capitalista, são a primeira ruptura da velha forma, embora naturalmente, em sua organização efetiva, por toda parte reproduzam e tenham de reproduzir todos os defeitos do sistema capitalista. Mas, dentro delas suprimiu-se a oposição entre capital e trabalho, embora ainda na forma apenas em que são os trabalhadores como associação os capitalistas deles mesmos, isto é, aplicam os meios e produção para explorar o próprio trabalho. Elas mostram como, em certo nível de desenvolvimento das forças produtivas materiais e das formas sociais de produção correspondentes, novo modo de produção naturalmente desponta e se desenvolve partindo do antigo. (Marx, 1979, p. 509).
} 


\section{Trabalhonecessário}

Issn: 1808 - 799X

ano 10, no $15-2012$

trabalhadores a partir do pós-guerra cujas contradições, longe de serem eliminadas, foram amortizadas pelo Estado de bem estar social "na era de ouro do capitalismo".

\section{A produção associada no Brasil}

A despeito de algumas iniciativas no início em fins do século XIX, é nas últimas décadas do século $X X$ que as cooperativas no Brasil ganham maior impulso em função da crise do trabalho assalariado a partir da década de 1970. (Singer, 1998, 2002; 2003; Picanço e Tiriba, 2004). Na década de $1980^{6}$, uma das ações organizadas pelos trabalhadores foi a tomada de empresas falidas, ou em vias de falência. Acrescido aos efeitos recessivos e a intensificação da mundialização do capital, pesa contra os trabalhadores a própria reestruturação produtiva $^{7}$.

Em 1991, tem-se o caso da empresa Markeli, fábrica de calçados em Franca, São Paulo, onde os trabalhadores dispuseram-se a uma luta política e assumiram o controle da fábrica, agonizante em dívidas. Trata-se de um marco, pois dá início a uma articulação dos trabalhadores em nível nacional, por meio do seu sindicato, que buscam apoio técnico junto a $\mathrm{CUT}^{8}$ e ao

\footnotetext{
${ }^{6}$ Um exemplo de iniciativa nesse sentido foi a Cáritas, entidade ligada à CNBB, que financiou milhares de pequenos projetos denominados PACs, Projetos Alternativos Comunitários que, dentre outros lugares, foram desenvolvidos em alguns assentamentos do MST. (Singer, 2002). Aliás, este movimento social trás em suas diretrizes a perspectiva cooperativista, uma de suas teses é de que as ocupações apontem para a formação de produções agrícolas na forma de cooperativas autogestionárias, o que acabou gerando os SCA, Sistema de Cooperativas de Assentados. Uma outra iniciativa que vincula o MST com o cooperativismo foi a criação da CONCRAB, Confederação das Cooperativas de Reforma Agrária.

${ }^{7}$ Face essa reação orgânica do capital, há uma maior presença do trabalho morto em detrimento do trabalho vivo, bem como a elevação das terceirizações e do trabalho compulsório que, dentre outras coisas, somam esforços para o aumento do desemprego, especialmente nas indústrias. (Tiriba, 2001, Picanço e Tiriba, 2004). Tauile (2007) lembra que na década de 1980 surgem as primeiras experiências marcadas por esse tipo de luta como os casos dos trabalhadores da Remington (RJ); Perticamps (SP) $e$ Caraíba Mineração (BA). (2007).

${ }^{8}$ Central única dos Trabalhadores.
} 


\section{Trabalhonecessário}

Issn: 1808 - 799X

ano 10, no $15-2012$

DIEESE9 . (Faria, 1997). É desta articulação, a criação da ANTEAG, Associação Nacional dos Trabalhadores em Empresas Autogestionárias ${ }^{10}$. Desde então, intensifica-se no Brasil diversas ações dos trabalhadores em se associar para produzir, dentre elas, a experiência da Metalcoop.

\section{Metalúrgicos produzindo, aprendendo e ensinando associadamente}

A Metalcoop é uma cooperativa fundada em 25 de agosto de 2002, por ex-funcionários da Picchi S/A Indústria Metalúrgica, cujo ponto de partida foi os atrasos salariais, não pagamento das férias e demais direitos trabalhistas. Todavia, antes de formarem essa cooperativa, os trabalhadores participaram ainda de comissões para acompanhar a gestão da empresa, as quais não só se mostraram ineficientes para resolver o problema financeiro, mas, inclusive, serviram de argumento dos antigos patrões que tentaram transferir para os trabalhadores a responsabilidade pelo fracasso da empresa. Diante dessa situação, os trabalhadores mobilizados e com inúmeras necessidades materiais buscaram se organizar para criar uma cooperativa ${ }^{11}$ :

\footnotetext{
${ }^{9}$ Departamento Intersindical de Estatísticas e Estudos Sócio-econômicos.

10 De fato, é um pouco mais tarde, em fins da década de 1990, que a CUT, Central Única dos trabalhadores, diante dos avanços na eliminação dos postos de trabalho e do posicionamento dos trabalhadores em assumir a produção, cria em 1999 a ADS, Agência de Desenvolvimento Solidário e mais tarde a Unisol Brasil. Outra ação articula o movimento sindical, movimentos sociais e as Universidades brasileiras, derivando a Rede de Incubadora Universitárias e as ITCPs, Incubadora Tecnológicas de cooperativas populares. (Barros, 2004).

${ }^{11}$ Depois de várias reuniões para buscar um acordo, chegaram a uma decisão, e, em 20 de Agosto de 2002, 121 trabalhadores foram demitidos, sendo que deste, vinte iniciaram a cooperativa, fundaram Metalcoop, e depois mais outros 67 se associaram. Até o ano de 2009, essa cooperativa era propriedade de 59 trabalhadores cooperados e empregava 51 trabalhadores. (SANTOS, 2010).
} 


\title{
Trabalhonecessário
}

Issn: $1808-799 X$

ano 10, no $15-2012$

\begin{abstract}
Aí nós nos reunimos com eles (...), quando eu cheguei, eu disse novamente que a gente tinha feito o dever de casa e eles não. (...). Ai eu falei, olha! Num é isso não, a partir de hoje nós queremos a oportunidade de dirigir a empresa, mais como é que é isso? A gente quer que vocês deixem a empresa, que a gente vai tocar. (...). Aí eles ficaram de pensar e passaram uns dias, eles disseram que não seria possível. (...), perguntamos sobre aqueles que não tinham FGTS, porque tinha oito anos que não era depositado, tinha gente que não tinha nada de fundo de garantia depositado. Ai eles ficaram sem saída, foi quando dissemos pra eles o seguinte, manda todo mundo embora que nos vamos criar uma cooperativa. (Cooperado, presidente da Metalcoop).
\end{abstract}

Para gerir associadamente a produção, esses trabalhadores tiveram que elaborar estratégias para organizar o processo de trabalho, lidando com a falta de experiência na gestão, ausência da prescrição da engenharia, desconfiança dos fornecedores e clientes e uma maquinaria que sob a gestão do capital não respondia as exigências da ciência e, tampouco, obtinha resultados tecnológicos. Por outro lado, a solidariedade instalada pela produção associada fez com que as relações sociais de produção atingissem uma comunhão pedagógica, era necessário ensinar e aprender para tocar o novo negócio. Como nos disse um trabalhador cooperado, o bom aqui é que apesar de toda dificuldade, nunca ninguém humilhou ninguém por não saber fazer as coisas. Posso te falar até o contrário, vi muitas vezes, o cara assumir que não sabia e receber o apoio dos outros, isso não acontece a toda hora por aí. (Cooperado, coordenador de manutenção). Portanto, senhas de uma pedagogia do trabalho potencializada pela produção associada. A experiência da Metalccop, indica que pelas próprias condições iniciais, o princípio educativo do trabalho tem forte vinculo com o trabalho real, antes mesmo que esse se estabeleça como uma resposta ao trabalho prescrito. Vejamos alguns casos

O processo de construção da Metalcoop valorizou a luta coletiva, questionando o mérito individual e a necessidade da haver um patrão e a 


\section{Trabalhonecessário}

Issn: 1808 - 799X

ano 10, no $15-2012$

revelação de que tinham virtudes subsumidas pela divisão do trabalho e por uma gestão embrutecida:

Cê vê um cara ali na prensa, o cara usa uma força danada pra trabalhar, o cara parece ser grosso. Aí, num processo igual o que passou com a gente, o cara vai lá, participa com idéias que na empresa privada ele nunca vai poder demonstrar, porque lá, no máximo, ele vai dar idéia só pra produção. Mas aqui não, quando tem problema de gestão, de relacionamento entre colegas, o cara tem espaço pra falar, mesmo de coisas mais complicadas. (Cooperado, diretor administrativo da Metalcoop).

Nesse sentido, a aprendizagem para os trabalhadores da Metalcoop, além de necessária para desenvolver a empresa, foi uma demanda do estatuto da produção associada, seja pela materialidade herdada e pelas relações sociais que este contexto engendra.

Há fatores que concorrem para que na Metalcoop existam possibilidades diferenciadas para a produção de saberes tácitos? Se no início, os cooperados tiveram a necessidade de recuperar a eficácia da maquinaria, improdutiva para os antigos donos, em pouco tempo, eles acabaram superando essa maquinaria "ineficaz" pelo uso de saberes que antes eram desprezados. Dessa forma, a perspectiva da produção associada que modificou a hierarquia de saberes da antiga empresa, mobilizou relações de trabalho mais favoráveis à incorporação da experiência e da técnica no desenvolvimento da tecnologia e na interpretação da ciência.

\section{Trabalhadores, políticos e técnicos: saberes na produção associada}

Diversos motivos nos permitem dizer que na Metalcoop há um aprofundamento daquilo que já ocorre na produção capitalista, a distância entre 


\section{Trabalhonecessário}

Issn: 1808 - 799X

ano 10, no $15-2012$

o "trabalho prescrito" e o "trabalho real"12, a saber, os limites de uma maquinaria condenada pelos antigos patrões, a falta de um aporte científico e, as peculiaridades de uma produção de associada, proponente, no caso da Metalcoop, de relações menos coercitivas, de sorte que se promoveu no trabalhador uma certa unidade entre o técnico e o político.

Ousamos destacar que diversas ações ocorridas na Metalcoop, se não totalmente novas, ao menos guardam algumas distâncias de práticas nas empresas privadas como, por exemplo, a autonomia para criar e o tratamento dado ao erro que são tidas pelos próprios cooperados como outra gestão diretamente responsável pelo crescimento da empresa. Vejamos uma que vincula a criatividade com o tratamento dado ao erro:

Nós temos aqui uma prática que não é não acusar quem erra, o cara pode ter errado hoje, mas ontem na hora que ele tomou a decisão, ela era a mais acertada (...) a experiência vem mostrando pra gente que errar pode ser o caminho pra descobrir novas formas de acertar. (cooperado, presidente da Metalcoop).

Para outro cooperado, as chances de aprender no trabalho são maiores na Metalcoop porque é possível errar, contrariar a visão da engenharia, e colher resultados que só são possíveis com tentativas reais, portanto, com algum custo:

Nem sempre a gente vai acertar na primeira vez. Pela experiência dá pra ter uma base, mas a gente erra também, isso faz parte do processo. O curioso é que quando tem erro, aí o cara vem e fala que sabia, que eu era teimoso e tudo mais. Já teve situação que eu pensei em desistir, mas cada erro é um aprendizado. Como a firma é nossa, a gente tem mais liberdade de errar, aí é

\footnotetext{
${ }^{12}$ De acordo com Santos (2000), trabalho prescrito é: a definição prévia da maneira como o trabalhador deve executar o trabalho: o modo de usar os equipamentos e as ferramentas, o tempo concedido para cada operação, o como fazer e as regras que devem ser respeitadas (2000, p. 344). O trabalho real se remete às condições necessárias em que se realiza uma parte do trabalho que sempre escapa à prescrição, portanto, o trabalho real é aquele que garante o andamento do processo de trabalho
} 


\section{Trabalhonecessário}

Issn: $1808-799 X$

ano 10, no $15-2012$

que mora o segredo, porque se você acerta, aí beleza, você vai pra casa contente. Se você erra, você conversa mais, pensa mais e de vagarzinho vai montando o seu banco de dados, sua própria ciência, isso é porque você errou. (Cooperado, gestor do processo de trabalho).

Dessa forma, a questão do erro na Metalcoop interroga o estatuto epistemológico e político da ciência, coloca o saber na teia das relações de poder, em que o erro e o acerto têm uma perspectiva mais coletiva e não absolutamente individualizada como nas empresas privadas:

(...) Normalmente, as empresas têm lá a engenharia dela e eles arriscam pouco porque o cara num vai querer perder a boca dele, o emprego dele. $O$ chefe acaba que nem arrisca né, e o peão também não, ele sabe que se der errado, a culpa vai ir toda pra ele. Agora, se der certo, é por causa da engenharia. No nosso caso, também, acho que ainda tem umas vaidades, mas é longe do que é lá fora, sem contar que todo mundo é dono e ninguém vai errar pra prejudicar ele mesmo (...). (Cooperado, torneiro mecânico da produção);

(...) Por isso, eu sempre digo que testar num é incompetência, é a nossa forma de ver se vai dar certo. A gente tem dúvida, a gente vai e combina, (...), deixa meia dúzia de peças, que nós vamos fazer um ensaio aí pra ver o que vai acontecer, se não deu certo ainda, mas andamos um bom pedaço do caminho. Temos que insistir, o que nós vamos fazer? Vamos modificar a ferramenta, vamos fazer um ajuste no ferramental pra gente tentar novamente? Vamos, então vamos fazer, é um caminho, a gente não pode achar que não deu certo e que está tudo errado, não deu certo ainda, mas pode dar certo. Vamos continuar tentando. Porque que o atleta que faz salto, ele salta 15 metros, e depois, amanhã, ele faz um salto de 16, depois faz 17 . Então são as tentativas que fazem com que você acabe alcançando outros resultados. (Cooperado, expresidente da Metalcoop).

Em outra fala, a apropriação pedagógica do erro aparece, ainda mais, vinculada ao fato da Metalcoop ser uma empresa de produção associada. Vejamos: 


\title{
Trabalhonecessário
}

Issn: 1808 - 799X

ano 10, no $15-2012$

\begin{abstract}
Como a empresa é nossa, nós pudemos ter mais ousadia. A literatura diz que você tem que fazer uma peça em tantas operações, os cálculos mandam serem feitos dessa forma. (...) Então, corre o risco de rebentar o ferramental, de colocar em risco até a vida da máquina. Teve um dia, o pessoal tava com medo e eu falei deixa pra sexta-feira, né? Sexta-feira, no final da tarde, a gente monta essa ferramenta e vamos experimentar, né? Se de fato aquilo que a gente acha que vai dar certo, que essa peça além de produzir, sem levar em conta a literatura pra (...). Bate, a peça acaba dando certo, cê acaba mostrando que nem sempre a literatura diz tudo, que precisa o homem ir um pouco mais além daquilo que são os limites. É aquilo que a gente sempre diz: O céu não pode ser o limite. Se a gente for um pouquinho mais acima do céu a gente vai descobrir que depois dele tem coisas bem interessantes a serem exploradas. (Cooperado, ex-presidente da Metalcoop).
\end{abstract}

O tratamento que os cooperados conferem aos erros no processo de trabalho e a presença daquilo que eles chamam de ousadia exemplifica que os avanços técnicos são atravessados por aspectos políticos.

Outro aspecto interessante no processo de trabalho na Metalcoop é o questionamento da eficiência técnica de uma hierarquia de saberes que subordina o chão de fábrica à gerência. No processo de trabalho desta cooperativa, há uma inversão de itinerário da prescrição, em que parte do processo de trabalho se inicia pelos pontos de vistas dos trabalhadores da produção, detentores dos saberes necessários para superar a maquinaria "defasada", saberes estes, não desprovido de elementos escolares, mas formalizados no e pelo trabalho.

Na Metalcoop, a elaboração do projeto da matriz, ao contrário da divisão clássica do trabalho, os cooperados, majoritariamente do chão de fábrica, elaboram uma espécie de pré-projeto que será traduzido na linguagem do desenho mecânico pela engenharia. Assim, temos uma inversão de rota, onde o pessoal da oficina faz uma "pré-prescrição" para os seus colegas do escritório. Tendo como base suas experiências anteriores, os cooperados 


\section{Trabalhonecessário}

Issn: $1808-799 X$

ano 10, no $15-2012$

compreendem que a fragmentação entre concepção e execução empobrece o processo de trabalho:

Aqui, nós somos quatro trabalhadores, com curso superior só tem eu, tem o Anderson e o Ricardo que fazem engenharia e o Zé que é um técnico, mas todos eles tem Senai. O Anderson e o Zé têm experiência na produção, isso ajuda muito e eu tenho trinta anos de extrusão a frio. Esse quadro é bem menor do que o que existia na Pichhi, mas estamos atendendo, mesmo porque, trabalhamos de forma bem diferente, a gente toma decisões ouvindo o pessoal da produção, então um projeto nosso não é de quatro pessoas da engenharia, na prática, ele é de sete, oito ou dez pessoas. (Cooperado, assistente industrial).

Seguindo por essa trilha, qualquer perspectiva de educação deve evitar tratar os saberes da experiência como resíduo do trabalho prescrito. Aliás, ousamos dizer que é necessário ampliar as definições sobre o saber tácito, ele não é mobilizado pela insuficiência da prescrição, podendo, inclusive, antecipála, dando mostras de que os trabalhadores pensam todo o tempo ${ }^{13}$.

$\mathrm{Na}$ confecção ${ }^{14}$ da matriz nos deparamos com as situações ilustrativas sobre as interfaces dos saberes dos cooperados da Metalcoop com a maquinaria da empresa, dentre algumas, encontramos a seguinte:

Olha só, está vendo essa retífica aqui? Ela é até muito boa se a gente olhar a idade dela. Só que a retifica é uma máquina final, ela é a última máquina antes de montagem, se eu matar uma peça na retífica, eu tô perdendo todo o serviço do torno da freza e o resto do processo. Essa retífica tem muito recurso, só que aqui tá cheio de folga. Se chegar um outro cara, ele vai apanhar um pouco, é por isso que o macete é necessário, senão num dava pra fazer quase nada. Tá vendo aqui, nesse caso aqui é só dá uma pressão, ou então tirar um pouquinho menos, porque ela vai cortar mais mesmo. Tem hora que você que dar mais um passe, aí é só repetir, sem tirar nada, ela tira sozinha, a própria folga, tira mais material. Então,

\footnotetext{
${ }^{13}$ Grifo nosso.

${ }^{14}$ Elaboração/confecção deve-se pela observação que nesta o processo de fabricação comporta alterações, visto que, ao não dispor de uma literatura a confecção é o próprio laboratório da concepção. Em outros termos, é se fazendo que se confirma as hipótese levantadas pelos trabalhadores.
} 


\section{Trabalhonecessário}

Issn: 1808 - 799X

ano 10, no $15-2012$

nesse caso eu uso o defeito da máquina a meu favor. (Cooperado, retificador ferramenteiro).

Assim, uma das vias do princípio pedagógico do trabalho é dada pela própria interface do trabalhador com a maquinaria, portanto, elucida que 0 trabalhador mobiliza saberes todo o tempo e não de forma residual, respondendo as lacunas do trabalho prescrito. E, ainda, percebe-se com clareza que a maquinaria como trabalho morto, logo, é inanimada sem o trabalho vivo, cuja ciência nela inscrita e falível frente ao desgaste, as variações do objeto de trabalho e todo tipo de imponderável. Já o trabalhador, mesmo com toda sorte de limitações, reage frente ao inesperado, subjuga e renormatiza as propriedades físicas da maquinaria.

Importante dizer que na Metalcoop, a distância entre o trabalho prescrito e o trabalho real não apenas confrontou a validade dos saberes teóricos com os saberes tácitos, mas também restabeleceu uma tensão entre os próprios sujeitos, portadores e "defensores" destas epistemologias. Se, para a maioria dos cooperados, há um prazer em constatar a validade de seus saberes postos às provas mais difíceis, o mesmo não se pode dizer sobre outro trabalhador, também cooperado, representante da ciência, imponderado nas empresas privadas, o engenheiro.

Nesse caso, as relações amistosas se viram estremecidas pelo lugar que saberes com distintas epistemologias ocupariam no processo de trabalho, já que na Metalcoop a experiência operária relativizava a hierarquia de saberes tradicionalmente favorável aos saberes da engenharia. A partir do momento em que se intensificou a participação dos cooperados de chão de fábrica no projeto da matriz e nas demais partes do processo de trabalho, iniciou-se uma disputa velada pelo monopólio do trabalho prescrito: 


\title{
Trabalhonecessário
}

Issn: 1808 - 799X

ano 10, no $15-2012$

\begin{abstract}
Hoje é fácil, chega alguém aqui e fala: é, os caras mudaram a matriz e encurtaram o processo, foi isso que eles fizeram. Só que tem as outras coisa, as dificuldades. Só pra você ter uma idéia, no início, o engenheiro nosso, ele já era engenheiro da Picchi e não começou com a gente na cooperativa, mas quando o serviço apertou e nós fomos e chamamos ele. No início, ele não aceitou de forma alguma as minhas sugestões, eu fui fazendo uns testes escondidos, a peça ia dando certo e ele achando que era o projeto dele. No dia que ele descobriu, ele ficou uma fera comigo, mesmo assim, mesmo dando certo e o pessoal falando pra ele, ele não aceitava. Pelo resultado das peças, ele teve que aceitar, mas punha muita barreira, sabendo que eu num sou bom no desenho, ele pedia pra eu desenhar e eu só faço croqui, sou fraco no desenho. Ficou uma relação ruim, e eu fui mostrando o resultado na prática e ele no cálculo, falando que num dava pra fazer. Ficou difícil, a verdade dele era de papel e a minha verdade era de aço, a gente não vende papel, a gente vende peça de verdade e acho que ele se sentiu menor, eu num tenho nada contra a pessoa, mas, também, se eu acreditava no que tava fazendo, eu tinha que defender meu conhecimento, e a prova tá aí pra quem quiser ver. (Cooperado, gestor do processo de trabalho);
\end{abstract}

Não exagero, então, dizer que o chão de fábrica, palco por excelência do trabalho produtivo, é uma escola, quase única, em que os saberes oriundos da experiência podem ser alçados num patamar capaz de indicar para a ciência engenharia superar e/ou complementar a ciência na produção de tecnologia, portanto, confere legitimidade aos trabalhadores do chão de fábrica para prescrever o processo de trabalho.

Também, em nosso entendimento, mesmo que inscrita em relações mercadológicas, a experiência dos cooperados da Metalcoop confirma que é o capital que depende do trabalho e não o contrário, dá mostras que não separa o homo sapiens do homo faber, como diria Gramsci, que o homem se faz pelo trabalho,e, por meio desse, domina a sua própria natureza. 


\section{Trabalhonecessário}

Issn: 1808 - 799X

ano 10, no $15-2012$

\section{Considerações finais:}

A experiência dos cooperados da Metalcoop que demonstram que o princípio educativo do trabalho pode encontrar na produção associada um terreno mais fértil. Mostra como a pobreza material pode ser compensada pelas faculdades humanas. Vimos fortes evidências que os trabalhadores, por estratégias individuais, ou coletivamente, aprenderam que para produzir associadamente seria necessário construir uma relação mais fraterna e sensível quanto à dúvida, a timidez, ou o medo do colega perante o desconhecido.

Assim, a socialização da experiência como necessidade para tocar o negócio, a liberdade para criar e direito ao erro, o confronto da técnica com a tecnologia e a ciência instalaram uma articulação de saberes de diversos níveis em uma trama pedagógica, integrando a técnica, tecnologia e ciência com a política, a economia e o social.

Nesse sentido, mesmo que timidamente, a produção associada da Metalcoop potencializou o "religamento" daquilo que o capital sempre buscou separar, uma solidariedade pedagógica entre os trabalhadores, a saber, a recomposição da totalidade, o uso respeitoso de linguagens diversas e o esforço e a boa vontade para aprender junto e com o outro.

Se, de um lado, a organização do processo de trabalho na Metalcoop ainda se pauta na divisão das tarefas, por outro lado, há uma tensão colocada pelo confronto da técnica com a tecnologia e a ciência que questiona a importância dessa divisão. Como vimos, em muitos casos, o saber dos trabalhadores desafiou e contrariou a ciência, ou como os cooperados gostam de dizer foram "além da literatura". Essa experiência de produção associada 


\section{Trabalhonecessário}

Issn: $1808-799 X$

ano 10, no $15-2012$

mostrou que a aprendizagem dos trabalhadores esteve vinculada ao fato de que eles buscaram se fazer, além de sujeitos "técnicos", também, sujeitos econômicos e políticos.

Dessa forma, uma educação sintonizada com os interesses dos trabalhadores pode se constituir pelo e no trabalho, portanto, uma via que confronta os saberes investidos com implicações sociais, políticas e econômicas, necessária para ultrapassar aquilo que Frigotto denuncia como "cidadão mínimo", (...) Um cidadão produtivo que faz bem feito o que se lhes pede e que "não se mete" no que não lhe cabe: discutir os rumos da economia, a política e seus interesses. Um cidadão mínimo. (Frigotto, 2004, p. 15).

Em Gramsci (1995); Rummert, (2007) há preciosas referências de que aos trabalhadores é necessária a apropriação da produção artística, cultural, científica e tecnológica do seu tempo. (...) a filosofia da práxis não busca manter os "simplórios" na sua filosofia primitiva do senso comum, mas busca, ao contrário, conduzi-los a uma concepção de vida superior. (1995, p. 20). A fala de um cooperado expressa um ponto de vista que elogia a aprendizagem no trabalho e critica a escola por estar mais, ou unicamente, vinculada à formação para o trabalho:

Num é fácil chegar nesse ponto, mas na cooperativa tudo favorece pras pessoas se juntarem, nas empresas privadas tudo ajuda pras pessoas se separarem. Por isso eu já falei, falei até na faculdade em que eu tô cursando, a escola devia conhecer as cooperativas, as escolas preparam para o mercado privado, se as escolas viessem até as cooperativas, estudassem o que se passa aqui, elas poderiam melhorar o ensino. Tem muito exemplo, igual eu te falei, aqui nós tiramos muito proveito do erro. Então se você voltar no exemplo da escola, ela põe aquele respeito pelo que já está escrito e ninguém questiona o escrito. Automaticamente, se todo mundo fica com medo de errar, ninguém vai tentar outro caminho. Pra mim e pra muita gente aqui na ficou essa coisa, a gente quer acertar, mas o acerto é um caminho duro, fazendo ali e conversando. Então, nas escolas você não faz e não vê o seu conhecimento, boa parte a pessoa fica mais copiando e num tem aquele tempo de acompanhar pra ver se sua idéia tá certa e nem troca idéias, é mais é concorrência. Comparando com a nossa experiência, posso dizer que a escola 


\section{Trabalhonecessário}

Issn: $1808-799 X$

ano 10, no $15-2012$

ensina pouco por causa dessas coisas, ao menos eu vejo assim. (Cooperado, presidente da Metalcoop).

Importante ressaltar que, ainda que destaquem os saberes oriundos da experiência, os cooperados também reconheceram que há necessidade de articulação destes com elementos científicos. Vejamos algumas falas:

É importante estudar, conhecer melhor a tecnologia na área de conformação mecânica. Eu falo pelo próprio Elias, ele já faz chover aqui sem ter muito estudo, então se ele estudasse, se ele fosse um engenheiro, ele faria chover mais. Ele podia fazer o que faz, mas teria mais facilidade pra explicar como fez, ele poderia fazer um projeto. Tem outros colegas que poderiam ir mais longe. A gente tem que lembrar que a cooperativa é diferente e num dá pra ficá só com a experiência. (Cooperado, assistente industrial);

A intensa produção de saberes na Metalcoop foi, sem dúvida, favorecida pelo estatuto da produção associada, cujas condições convocaram a experiência para destravar e garantir o andamento da produção. Ao assumir um lugar de destaque, a experiência não só impactou na capacidade produtiva, mas, também, na organização do processo de trabalho. Tensões antigas foram superadas, amortecidas ou eliminadas, mas outras apareceram como, por exemplo, aquelas surgidas de uma hierarquia de saber que equilibra a relação engenharia e chão de fábrica. Como vimos, a prescrição do chão de fábrica para a engenharia exigiu que a experiência além de desafiar a ciência, ainda se valesse, talvez só por isso, do estatuto político dado pelo fato de todos os cooperados são donos, ou seja, do caráter da produção associada.

Do ponto de vista de uma reflexão sobre a contribuição dessa experiência para uma suposta apropriação da educação escolar, salientamos que um ponto que nos parece crucial, a noção de que uma educação que leve em conta os interesses dos trabalhadores não pode separar o sujeito 


\section{Trabalhonecessário}

Issn: $1808-799 X$

ano 10, no $15-2012$

epistemológico do sujeito axiológico, sujeito econômico do sujeito político, cultural.

Ainda sobre as heranças do mundo do trabalho para a educação, especialmente a de caráter escolar, gostaríamos de apontar a necessidade de demarcar que o trabalho, por tudo que é para o homem, extrapola o campo de atuação e os domínios da disciplina, inter e/ou trans, pois nele se inscrevem saberes, valores e subjetividades que não são abarcadas pela abordagem disciplinar. Essa carece de conhecimento e método para uma empreitada desse tamanho. O mundo do trabalho nos lega inúmeras experiências dos trabalhadores para que educadores populares e acadêmicos pensem e organizem a educação, escolar e não escolar, e a vida social que dela não se descola. Conquanto que a educação para a grande maioria dos brasileiros e educação está longe da "escola unitária" de Gramsci, ao menos, os trabalhadores na produção associada confirmam a força pedagógica do aprender em comunhão defendido por Paulo Freire. 


\section{Trabalhonecessário}

Issn: 1808 - 799X

ano 10, no $15-2012$

Referências bibliográficas

ANTUNES, R. Os sentidos do trabalho: ensaio sobre a afirmação: negação do trabalho. 3 ed. São Paulo: Boitempo, 2001. 258p.

BARROS, J. O projeto educativo das ITCP's: encontros e desencontros na incubagem de cooperativas populares. In: TIRIBA, LIA e PICANÇO, IRACY. Trabalho e Educação. Aparecida, São Paulo: Idéias e Letras, 2004.

BRAVERMAM, H. Trabalho e capital monopolista: a degradação do trabalho no século XX. Rio de Janeiro: Guanabara, 1987.

CATTANI, D. Dicionário crítico sobre trabalho e tecnologia. Petrópolis: Vozes; Porto Alegre: Ed. Da UFRGS, 2002.

CUNHA, DAISY et AL (ORG). Trabalho: minas de saberes e valores. Belo Horizonte: NETE/FAE/UFMG, 2007.

ENGELS, F. Do socialismo Utópico ao Socialismo Científico. São Paulo: Centauro, 2005.

FRIGOTTO, G. Prefácio. In: Economia popular e cultura do trabalho. ljuí: UNIJUÍ, 2001.

Prefácio. In: Tiriba, Lia e Picanço, Iracy. Trabalho e Educação. Aparecida, São Paulo: Idéias e Letras, 2004.

A ideologia que embala a galinha dos ovos de ouro.

Tiriba, Lia e Picanço, Iracy.. Trabalho e Educação. Aparecida, São Paulo: Idéias e Letras, 2004.

GRAMSCI, A. Concepção dialética da história. 10. ed. Rio de Janeiro: Civilização Brasileira, 1995.

Brasileira, 2001.

Cadernos do cárcere, vol. 4. Rio de Janeiro: Civilização

. Maquiavel, a Política e o Estado moderno. Rio de Janeiro:

Civilização Brasileira, 1979.

HOBSBAWM, E et all. História do Marxismo: o marxismo no tempo de Marx. Rio de Janeiro: Paz e Terra, 1979. 


\section{Trabalhonecessário}

Issn: 1808 - 799X

ano 10, no $15-2012$

JUNIOR, J. D. S. Trabalho como princípio educativo. In: FIDALGO \& MACHADO. Dicionário da educação profissional. Belo Horizonte. Nete/FAE/UFMG, 2000.

LIMA, F. P. A; SILVA, C. D. A objetivação do saber prático na concepção de sistemas especialistas: das regras formais às situações da ação. Belo Horizonte, 1998. (Mimeo).

A engenharia da produção solidária. Trabalho e Educação. Belo Horizonte: Nete/FAE-UFMG. Vol 12, n. 1, p. 115-126, jan./jun. 2003.

NETE/FAE/UFMG, 2007.

. Trabalho: minas de saberes e valores. Belo Horizonte:

MARX, K. Manuscritos econômico-filosóficos. Os pensadores. São Paulo: Abril Cultural, 1978.

O capital: crítica da economia política. São Paulo: Nova Cultural. VI, II e III, 1985.

1975.

. Capítulo VI Inédito de O Capital. Porto: Publicações escorpião,

MARX, K.; ENGELS, F. Manifesto do partido comunista. 7. ed. São Paulo: Global, 1988.

NOSELLA, P. O trabalho como princípio educativo em Gramsci. Porto Alegre: Artes

Médicas, 1991.

A escola de Gramsci. Porto Alegre: Artes Médicas, 1992

NOVAES, H. T. O fetiche da tecnologia. São Paulo: expressão popular, 2007.

PERROT, M. Os excluídos da História: mulheres, operários e prisioneiros.

Rio de Janeiro: Paz e Terra, 1992.

PINTO, A. P. O conceito de tecnologia. Rio de Janeiro: Contraponto, 2005.

Pluiggrós, A et all. La fábrica del conocimiento. Los sabers socialmente produtivos en América Latina. Rosário: Homo Sapiens, 2004. 


\section{Trabalhonecessário}

Issn: 1808 - 799X

ano 10, no $15-2012$

RUMERTT, S. M. A "marca social" da Educação de Jovens e Adultos Trabalhadores. Trabalho e Educação. Belo Horizonte: Nete/FAE-UFMG. Vol. 17, n. 3, p. 13-29, set./dez. 2008.

. Gramsci, Trabalho e Educação: jovens e adultos pouco escolarizados no Brasil actual. Cadernos Sísifo 4, 2007.

SALERNO, M. S. Trabalho e organização na empresa industrial integrada e flexível. In: FERRETI, C. J. et al. (Org.). Novas tecnologias, trabalho e educação: um debate multidisciplinar. Petrópolis: Vozes, 1994.

SANTOS, E. H. Ciência e cultura: uma outra relação entre saber e trabalho. Trabalho e Educação. Belo Horizonte: Nete/FAE-UFMG, n. 7, p. 119-130, jul./dez. 2000.

SANTOS, E. H. Trabalho prescrito e real no atual mundo do trabalho. Trabalho e Educação. Belo Horizonte: Nete/FAE-UFMG, n. 1, p. 13-27, fev./jul. 1997.

SANTOS, E. H. Saber tácito, trabalho prescrito, trabalho real. In: FIDALGO \& MACHADO. Dicionário da Educação Profissional. Belo Horizonte: Nete/FAE/UFMG, 2000.

SANTOS, G, M e SANTOS, E. H. Contribuições da Pedagogia da Ferramenta para uma pedagogia do trabalho. Educação Unisinos, v. 10, p. 102-110, 2006.

SANTOS ALVES, GERALDO MÁRCIO. A pedagogia da ferramenta: estratégias de produção, mobilização e formalização de saberes tácitos criadas pelos ferramenteiros de uma indústria metalúrgica. Dissertação de mestrado. FAE/UFMG, 2004.

SANTOS, Geraldo Márcio Alves. Pacto para viver: a mobilização de saberes na produção associada, gestão e organização do processo de trabalho e maquinaria em uma indústria metalúrgica. Tese de doutorado. UFF, 2010.

SAVIANI, D. Trabalho e Educação: fundamentos ontológicos e históricos. Apresentado no GT Trabalho e Educação, durante a 29 Reunião Anual da ANPED, Realizada em Caxambu, 2006.

SINGER, P. Utopia militante: repensando o socialismo. Petrópolis: Vozes, 1998. 


\section{Trabalhonecessário}

Issn: 1808 - 799X

ano 10, no $15-2012$

Abramo, 2002.

Introdução à Economia Solidária. São Paulo: Fundação Perseu

. Economia solidária. In: CATTANI, A. D. A outra economia. Porto Alegre: Veraz Editores, 2003.

TAUILE, J. $\mathrm{R}$ et all. Empreendimentos autogestionários provenientes de massas falidas: relatório final. Brasília: MTE, IPEA, ANPEC, SENAES, 2005.

THOMPSON, E. A Formação da Classe Operária Inglesa. Rio de Janeiro: Paz e Terra, 1987. V 3.

Janeiro: Civilização Brasileira, 2002.

TIRIBA, L. Economia popular e cultura do trabalho. ljuí: UNIJUÍ, 2001.

Ciência econômica e saber popular: reivindicar o "popular" na economia e na educação. In: TIRIBA, LIA e PICANÇO, IRACY. Trabalho e Educação. Aparecida, São Paulo: Idéias e Letras, 2004. 